\section{Movement disorders among adult neurological outpatients evaluated over 20 years in Guayaquil, Ecuador}

\author{
Oscar H. Del Brutto,1,2 \\ Victor J. Del Brutto² \\ 1School of Medicine, Especialidades \\ Espíritu Santo University, Guayaquil; \\ 2Department of Neurological Sciences, \\ Kennedy Clinic, Guayaquil, Ecuador
}

\section{Abstract}

There is little information available on the evolutive pattern of patients with movement disorders in developing countries. We analyzed 579 consecutive adults with movement disorders and prospectively evaluated them at our institution (Department of Neurological Sciences, Kennedy Clinic, Guayaquil, Ecuador) from 1990 to 2009 . Mean age was $62.9 \pm 17.5$ years, and $50.8 \%$ were men. Patients presented with tremor/rigidity (55\%), involuntary movements (23.5\%) and abnormalities of stance and gait (21.5\%). Overall, $45 \%$ of our patients had degenerative disorders of the nervous system. We found significant increases in the relative prevalence of tremor/rigidity and abnormalities of stance and gait, and this reflected an increase in the number of patients with degenerative diseases over the study years. We found a dynamic pattern of movement disorders over the years. Today, causes and relative prevalence of these conditions in our population is more similar to that reported from the developed world than it was 20 years ago.

\section{Introduction}

Movement disorders are common reasons for consultation among adults attending outpatient neurological clinics.1,2 Due to the nature and pathogenic mechanisms involved in their occurrence, the prevalence of these complaints is supposed to be higher in developed countries where populations are older and their exposure to a number of industrial toxic factors is greater than in developing countries. Those risk factors may be counterbalanced by the number of patients with movement disorders related to infections of the central nervous system (CNS) and by environmental conditions that are more prevalent in the developing world. ${ }^{3-8}$ Indeed, some epidemiological surveys and hospital-based registries have shown that the prevalence of at least one of the most common cause of movement disorders
(Parkinson's disease) does not differ significantly between developed and developing nations. 9,10 However, these studies are crosssectional, providing no information on the variation in the relative prevalence of movement disorders over the years. Together with the increased life expectancy in the developing world, there are an increasing number of individuals with age-related neurological disorders attending outpatient clinics in those regions. ${ }^{11}$ We present a series of 579 adult neurological outpatients primarily presenting with movement disorders to describe their profile and to analyze variations in the relative prevalence of these manifestations and their causes over two decades.

\section{Materials and Methods}

From January 1990 to December 2009, 579 adults consulting primarily for a movement disorder were evaluated in our hospital. They represented $7.7 \%$ of a total of 7519 outpatients aged 18 years or over who were evaluated by one of the authors (OHD) during this 20-year period.

Ethical aspects of the investigation and confidentially of the names of the patients included were assured by the institutional review board (IRB) of Hospital-Clínica Kennedy, Guayaquil (IORG0003481, FWA00006867). In addition, methodology and operational definitions of this study have been described elsewhere. ${ }^{12}$ In brief, patients were prospectively admitted using a unified format of clinical history which allowed comparisons by the end of the study. We analyzed data concerning demographics, type of movement disorder, diagnosis, and follow up. We then correlated the profile of patients included in each of the 5-year periods (1990-1994, 1995-1999, 2000-2004, and 2005-2009) to evaluate the occurrence of changes in the pattern of expression of the different movement disorders over the years. Data were independently reviewed by the authors and disagreements in data abstraction were resolved through discussion and consensus. $\chi^{2}$ and the Fisher's exact tests were used to assess the significance of the difference between the variables analyzed. $\mathrm{P}<0.05$ was considered significant. Statistical analysis of data was carried out using Epi InfoTM 7 software (Centers for Disease Control, Atlanta, GA, USA).

\section{Results}

Table 1 summarizes the main results of patients included in this study. The 579 patients had a mean age of $62.9 \pm 17.5$ years
Correspondence: Oscar H. Del Brutto, Air Center 3542, P0 Box 522970, Miami, FL 33152-2970, USA. Tel. +1.593 .42285790$

E-mail: oscardelbrutto@hotmail.com

Key words: movement disorders, Parkinson's disease, involuntary movements, tremor, neurological outpatients, Ecuador, neurological outpatients.

Contributions: the authors contributed equally.

Conflict of interests: the authors declare no potential conflict of interests.

Received for publication: 28 February 2013.

Accepted for publication: 6 May 2013

This work is licensed under a Creative Commons Attribution NonCommercial 3.0 License (CC BYNC 3.0).

(C) Copyright O. Del Brutto and V.J. Del Brutto., 2013

Licensee PAGEPress, Italy

Neurology International 2013; 5:e18

doi:10.4081/ni.2013.e18

and 294 (50.8\%) were men. Classification of patients into four 5 -year periods according to the year of first evaluation showed that 124 (21.4\%) were evaluated between 1990 and 1994, 140 (24.2\%) between 1995 and 1999, 146 (25.2\%) between 2000 and 2004, and 169 (29.2\%) between 2005 and 2009. The relative prevalence of patients with movement disorders increased when compared with the total number of patients seen at the clinic over the years of the study (from 6.5\% in 1990-1994, to 9.3\% from $2005-2009 ; \chi^{2}=10.13 ; \mathrm{P}<0.001$ ). The percentage of patients with movement disorders also increased with age, with $68.4 \%$ (396 of 579 ) being 60 years of age or older. When compared with the cohort of 7519 patients, 183 out of a total of 5166 patients under the age of 60 years and 396 of a total of 2353 patients aged 60 years or older, had a movement disor$\operatorname{der}\left(3.5 \%\right.$ vs $\left.16.8 \% ; \chi^{2}=401 ; \mathrm{P}<0.0001\right)$.

From the clinical point of view, 318 patients (55\%) presented with tremor/rigidity, 136 (23.5\%) with involuntary movements (tics, dystonia, myokymia, chorea, athetosis, ballismus), and the remaining 125 (21.5\%) with abnormalities of stance and gait. In general, patients with involuntary movements were younger and were less often men than those with tremor/rigidity and with abnormalities of stance and gait (mean ages: 49.8 \pm 19.4 , $65.7 \pm 14.3$, and $70.1 \pm 15$ years; percentage of men: $44.9 \%, 52.2 \%$, and $53.6 \%$, respectively). The relative prevalence of patients with involuntary movements remained stable during the 20 years of the study. However, relevance of tremor/rigidity and of abnormalities of stance 
Table 1. Characteristics of $\mathbf{5 7 9}$ outpatients presenting with movement disorder.

\begin{tabular}{|c|c|}
\hline Demographics & N. \\
\hline Mean age, years & $62.9 \pm 17.5$ \\
\hline Male gender & $294(50.8 \%)$ \\
\hline $\begin{array}{l}\text { Age group } \\
18-59 \text { years } \\
\geq 60 \text { years }\end{array}$ & $\begin{array}{l}183(31.6 \%) \\
396(68.4 \%)\end{array}$ \\
\hline $\begin{array}{l}\text { Years of evaluation } \\
1990-1994 \\
1995-1999 \\
2000-2004 \\
2005-2009\end{array}$ & $\begin{array}{l}124(21.4 \%) \\
140(24.2 \%) \\
146(25.2 \%) \\
169(29.2 \%)\end{array}$ \\
\hline $\begin{array}{l}\text { Syndromic diagnosis } \\
\text { Tremor/rigidity } \\
\text { Involuntary movements } \\
\text { Abnormalities of stance and gait }\end{array}$ & $\begin{array}{l}318(54.9 \%) \\
136(23.5 \%) \\
125(21.6 \%)\end{array}$ \\
\hline $\begin{array}{l}\text { Category of neurological disease } \\
\text { Degenerative diseases of the CNS } \\
\text { Diseases of uncertain/unknown etiology } \\
\text { Cerebrovascular disorders } \\
\text { Systemic, metabolic, iatrogenic conditions } \\
\text { Primary disturbances of CSF circulation } \\
\text { Neoplastic diseases of the CNS } \\
\text { Infections of the CNS } \\
\text { Inflammatory/autoimmune disorders } \\
\text { Congenital malformations or diseases }\end{array}$ & $\begin{array}{c}260(44.9 \%) \\
207(35.8 \%) \\
56(9.7 \%) \\
24(4.2 \%) \\
13(2.2 \%) \\
9(1.6 \%) \\
6(1 \%) \\
2(0.3 \%) \\
2(0.3 \%)\end{array}$ \\
\hline $\begin{array}{l}\text { Most common specific diagnosis } \\
\text { Parkinson's disease } \\
\text { Essential tremor } \\
\text { Cerebral infarction } \\
\text { Senile gait } \\
\text { Focal myokymia }\end{array}$ & $\begin{array}{c}198(34.2 \%) \\
86(14.9 \%) \\
47(8.1 \%) \\
44(7.6 \%) \\
34(5.9 \%)\end{array}$ \\
\hline
\end{tabular}

CNS, central nervous system; CSF, cerebrospinal fluid.

and gait both steadily increased over the study years from $21.7 \%$ to $30.2 \%\left(\chi^{2}=5.96 ; \mathrm{P}<0.01\right)$ and from $17.6 \%$ to $28 \%\left(\chi^{2}=3.84 ; \mathrm{P}<0.05\right)$, from 1990-1994 to 2005-2009, respectively.

Overall, 260 (44.9\%) of patients had degenerative diseases of the nervous system, $56(9.7 \%)$ had cerebrovascular disorders, 24 (4.2\%) had systemic, metabolic, or iatrogenic conditions, $13(2.2 \%)$ had primary disturbances in cere- stant over the study years, that of some other conditions increased with age; cerebrovascular and degenerative diseases, as well as primary disturbances in CSF circulation were more frequent in patients aged 60 years or older. The percentage of patients included in each of the different categories of neurological diseases according to the specific type of movement disorder is detailed in Table 2. Degenerative disorders predominated among patients with tremor/rigidity, while most patients with abnormalities of stance and gait had cerebrovascular disorders, and patients with involuntary movements most often had degenerative diseases or diseases of uncertain/unknown etiology.

Most common specific diagnoses in our patients were: Parkinson's disease in 198 (34.2\%), essential tremor in 86 (14.9\%), cerebral infarction in $47(8.1 \%)$, senile gait in 44 (7.6\%), and focal myokymia in 34 (5.9\%). Together, these conditions represented $70 \%$ of the patients included in this cohort.

A total of 65 patients (11.2\%) had had preexisting symptomatic neurological diseases that occurred from months to years before the initial visit. Most common pre-existing conditions were symptomatic cerebral infarction $(n=27)$ and cognitive impairment $(n=7)$. Fortyone patients were evaluated in their follow up for a different condition than that leading to the initial visit. The two most common conditions were cognitive decline in 16 patients and a cerebral infarction in 6 . In addition, 7 patients developed dyskinesia related to the use of L-dopa.

brospinal fluid (CSF) circulation, 9 (1.6\%) had neoplastic diseases of the central nervous system, $6(1 \%)$ had infections of the nervous system, $2(0.3 \%)$ had inflammatory/autoimmune disorders, and $2(0.3 \%)$ had congenital malformations or diseases. The remaining 207 patients (35.8\%) had a disease of uncertain/unknown etiology. While the relative prevalence of these conditions remained con-

\section{Discussion and Conclusions}

We noted a significant increase in the relative prevalence of movement disorders among our neurological outpatients over the years of the study (from $6.5 \%$ to $9.3 \% ; \mathrm{P}<0.001$ ). This correlated with the increased prevalence of

Table 2. Percentage of patients included in the different categories of neurological diseases according to type of movement disorder.

\begin{tabular}{|c|c|c|c|c|c|c|c|c|c|}
\hline & $\begin{array}{c}\text { Diseases } \\
\text { of uncertain } \\
\text { or unknown } \\
\text { etiology }\end{array}$ & $\begin{array}{c}\text { Degenerative } \\
\text { diseases } \\
\text { of CNS }\end{array}$ & $\begin{array}{l}\text { Cerebro- } \\
\text { vascular } \\
\text { disorders }\end{array}$ & $\begin{array}{l}\text { Systemic, } \\
\text { metabolic } \\
\text { iatrogenic } \\
\text { conditions }\end{array}$ & $\begin{array}{c}\text { Primary } \\
\text { disturbances } \\
\text { of CSF } \\
\text { circulation }\end{array}$ & $\begin{array}{l}\text { Neoplastic } \\
\text { diseases } \\
\text { of CNS }\end{array}$ & $\begin{array}{l}\text { Infections } \\
\text { of CNS }\end{array}$ & $\begin{array}{l}\text { Inflammatory } \\
\text { and } \\
\text { autoimmune }\end{array}$ & $\begin{array}{c}\text { Congenital } \\
\text { malformation } \\
\text { or diseases } \\
\text { disorders }\end{array}$ \\
\hline $\begin{array}{l}\text { Tremor/ } \\
\text { rigidity } \\
(n=318)\end{array}$ & 30.8 & 64.5 & 1.3 & 2.2 & - & 0.3 & 0.9 & - & - \\
\hline $\begin{array}{l}\text { Involuntary } \\
\text { movements } \\
(\mathrm{n}=136)\end{array}$ & 47.8 & 37.5 & 4.4 & 8.1 & - & - & 0.7 & - & 1.5 \\
\hline $\begin{array}{l}\text { Abnormalities } \\
\text { of stance } \\
\text { and gait } \\
(\mathrm{n}=125)\end{array}$ & s & 3.2 & 36.8 & 4.8 & 10.4 & 6.4 & 1.6 & 1.6 & - \\
\hline
\end{tabular}

CNS, central nervous system; CSF, cerebrospinal fluid. 
degenerative disorders of the nervous system during the past two decades. These findings concur with the concerns of the Pan American Health Organization who consider that degenerative diseases of the nervous system and stroke (instead of infections) will constitute the next health epidemics in Latin America. ${ }^{13}$

Comparison of our findings with other series of neurological outpatients is difficult since most descriptions do not focus on patients with movement disorders but merge neurological symptoms and diseases appearing in different age groups. ${ }^{1,2}$ What is clear from the literature is that tremor/rigidity (as a reflection of Parkinson's disease and related disorders) has become a major symptom among neurological outpatients from the developing world during the past years. ${ }^{11,14}$ In our patients, the relative prevalence of involuntary movements remained constant over the years of study, but there was a significant increase in prevalence of tremor/rigidity (from $21.7 \%$ to $30.2 \% ; \mathrm{P}<0.01$ ).

Our study shows a dynamic pattern of movement disorders in neurological outpatients over the past 20 years. We have not yet reached the rather high prevalence of degenerative diseases of the nervous system reported in some European studies focusing on neurological outpatients but, based on our findings, we can anticipate an increasing number of such patients over the next few years. Indeed, current distribution of degenerative diseases of the nervous system in our population is now more similar to that reported from the developed world than it was 20 years ago.11,12 Contrary to what could have been expected, we did not have a significant number of patients with infections of the nervous system or with tropical toxic conditions responsible for the occurrence of movement disorders in our series.

While the present study has the potential weakness of having been performed at a single medical center, it has the strength of a systematic methodology using similar diagnostic criteria for all patients included. To our knowledge, this is the only reported Latin American series of neurological outpatients presenting with movement disorders studied over two decades, analyzing not only variations in the reasons for consultation and diagnosis, but also the prevalence of pre-existing neurological disorders, as well the appearance of new conditions during follow up. Similar studies are needed to confirm our findings in other populations in the developing world and to compare them with those reported from Europe and the US.

\section{References}

1. Stone J, Carson A, Duncan R, et al. Who is referred to neurology clinics? The diagnosis made in 3781 new patients. Clin Neurol Neurosurg 2010;112:747-51.

2. Perkin GD. An analysis of 7836 successive new outpatient referrals. J Neurol Neurosurg Psychiatry 1989;52:447-8.

3. Kumar A. Movement disorders in the tropics. Parkinsonism Relat Disord 2002;9:6975.

4. Troiano AR, Micheli F, Alarcón F, Teive HAG. Movement disorders in Latin America. Parkinsonism Relat Disord 2006;12:125-38.

5. Alarcón F, Dueñas G, Cevallos N, Lees AJ. Movement disorders in 30 patients with tuberculous meningitis. Mov Disord 2000;15:561-9.

6. Caparros-Lefebvre D, Elbaz A. Possible relation of atypical parkinsonism in the French West Indies with consumption of tropical plants: a case-control study. Caribbean Parkinsonism Study Group. Lancet 1999;354:281-6.

7. Cosentino C, Torres L, Scorticati MC, Micheli F. Movement disorders secondary to adulterated medication. Neurology 2000;55:598-9.

8. Del Brutto OH, Santibáñez R, Santamaría M. Prevalence of Parkinson's disease in a rural village of coastal Ecuador. A twophase door-to-door survey. Acta Neurol Belg 2013 Jan 29. [Epub ahead of print].

9. Nicoletti A, Sofia V, Bartoloni A, et al. Prevalence of Parkinson's disease: a doorto-door survey in rural Bolivia. Parkinsonism Relat Disord 2003;10:19-21.

10. Zhang ZX, Roman GC, Hong Z, et al. Parkinson's disease in China: prevalence in Beijing, Xian, and Shanghai. Lancet 2005;365:595-7.

11. Del Brutto VJ, Del Brutto $\mathrm{OH}$. Characteristics of 478 very old neurologic outpatients evaluated over 20 years in Guayaquil, Ecuador. Acta Neurol Belg 2012;112:161-5.

12. Del Brutto VJ, Tettamanti D, Del Brutto $\mathrm{OH}$. Changing profile of 7,519 neurologic outpatients evaluated over 20 years. Eur Neurol 2012;68:381-90.

13. Pan American Health Organization. Health conditions in the Americas 1994, vol 1. Washington DC: P.A.H.O. Science Publications; 1994. pp 217-25.

14. Siddiqi OK, Atadzhanov M, Birbeck GL, Koralnik IJ. The spectrum of neurological disorders in a Zambian tertiary care hospital. J Neurol Sci 2010;290:1-5. 